ONE HUNDRED AND SEVENTY-FIFTH SCIENTIFIC MEETING

SEVENTY-THIRD SCOTTISH MEETING

THE ROYAL INFIRMARY, EDINBURGH

30 OCTOBER 1965

\title{
DIET AND DIABETES
}

\author{
Chairman : Professor R. H. Girdwood, MD, PhD, FRCP, FRCP Ed., Department \\ of Therapeutics, The Royal Infirmary, Edinburgh
}

\section{The glucose-fatty acid cycle and the aetiology of diabetes}

\section{By C. N. Hales, Department of Biochemistry, Tennis Court Road, Cambridge}

For many years it has been known that the body's energy requirements may be provided by the oxidation of carbohydrate, fat or protein and that of these three energy sources carbohydrate and fat are quantitatively the most important. It was also realized that under most physiological conditions the cells of the body are provided with more than one of these possible energy sources. Thus unless the cell's energy production is regulated solely by the availability of respiratory fuel the cell must be capable of selecting a fuel and simultaneously reducing the consumption of alternative fuels (Krebs, I935). Although the latter conclusion is relatively longstanding the mechanism of selection and the consequence of its derangement are recent discoveries. This improved understanding of the metabolic regulation of carbohydrate and fat oxidation has suggested a new approach to the investigations of the aetiology and treatment of diabetes mellitus.

Studies of the effects of the oxidation of ketone bodies and fatty acids on glucose metabolism in vivo and in vitro have shown that both ketone bodies and fatty acids inhibit glucose oxidation by muscle (for review see Randle, Garland, Hales, Newsholme, Denton \& Pogson, I966). This effect is observed in the presence of high concentrations of insulin as a reduction in the effect of insulin on glucose utilization by muscle. Ketone bodies and fatty acids may therefore be considered in this respect as powerful insulin antagonists. These observations coupled with the known effect of glucose and insulin on the storage of fatty acids as triglyceride have been integrated into the overall concept of a glucose-fatty acid cycle (Randle, Garland, Hales \& Newsholme, I963). There are essentially two levels of this cycle. The first is nutritional and refers to the alternate periods of feeding and fasting which characterize the $24 \mathrm{~h}$ cycle of feeding habits. Starting with an overnight fast during which the major energy requirements are provided by the oxidation of fat there follows the intake of food. There is a rapid suppression of fat oxidation and the onset of carbohydrate oxidation and storage. Depending on the speed of assimilation of food and the interval between meals, there then follows a brief period of fat oxidation followed again by feeding and a change to carbohydrate oxidation and so on until the period of overnight fast returns. 
This nutritional cycle is reflected at the metabolic level by changes in the rate of breakdown and synthesis of triglyceride providing the intracellular component of the cycle (Fig. I). At its most simple level, control of this cycle may be exerted through the presence or absence of glucose. In the absence of glucose, fatty acyl CoA

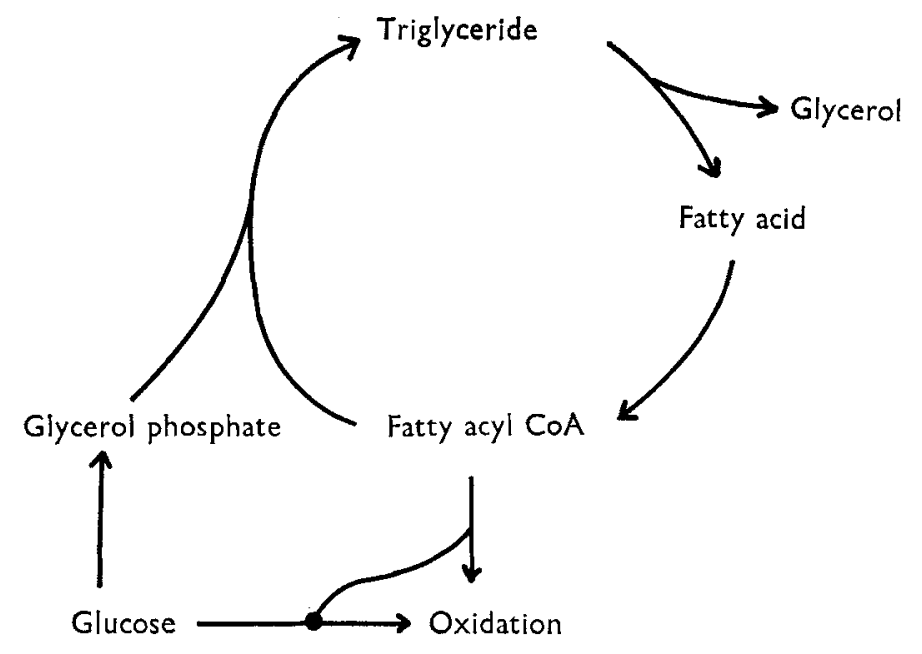

Fig. I. The glucose-fatty acid cycle. -o, inhibition.

is utilized for oxidation. In the presence of glucose, glycerol phosphate, an obligatory precursor of triglyceride synthesis, is increased, fatty acyl CoA is removed to triglyceride and glucose is oxidized. Multicellular organisms have superimposed on this basic mechanism the action of hormones. The activity of the enzyme hydrolysing triglycerides in adipose tissue is increased by adrenaline, glucagon, ACTH growth hormone and many other hormones and this effect is reduced by insulin (Ball \& Jungas, 1964; Fain, Kovacev \& Scow, 1965). The access of glucose to the cell interior is often dependent upon the action of hormones such as insulin which stimulates glucose uptake by muscle and adipose tissue and cortisol which reduces glucose uptake by adipose tissue (Munch \& Koritz, 1962). Most tissues possess the capacity for hydrolysing triglyceride and re-esterifying fatty acids. However much of the body's triglyceride store is in adipose tissue cells and therefore the regulation of the cycle in this tissue is of particular importance. Fatty acid released from adipose tissue provides the main source of fat for oxidation during periods of fasting. The fatty acids released by adipose tissue are now known to have profound effects on the metabolism of muscle and liver. An attempt has been made to indicate a few of these effects in Fig. 2.

Fatty acids appear to be taken up by tissues at a rate determined by their concentration (see review by Carlson, Boberg \& Hogstedt, 1965). This implies that the absolute level of fatty acid in plasma is a factor of very great importance in metabolic regulation, quite as significant for example as the concentration of glucose and insulin. Intracellular fatty acid is converted into fatty acyl CoA which may then be 


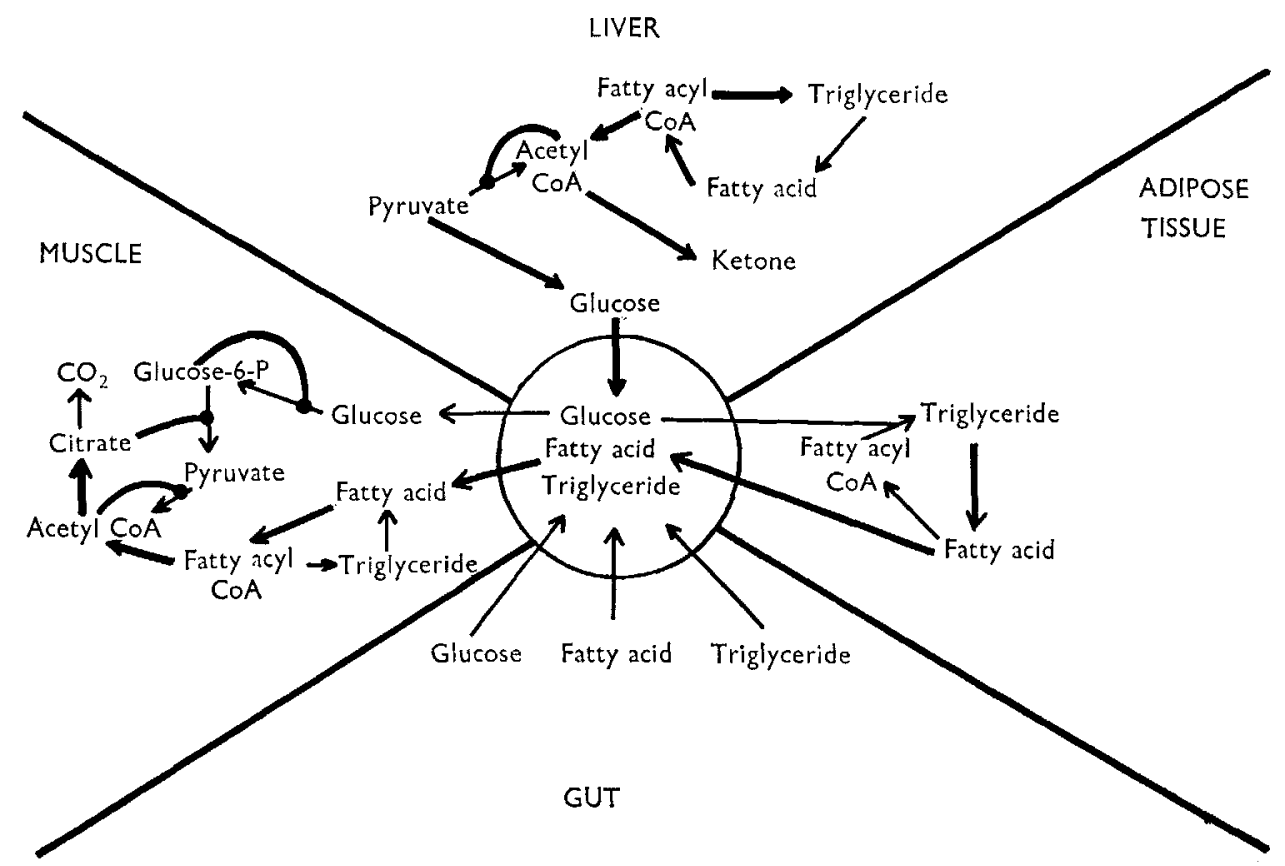

Fig. 2. Relationship between lipid and glucose metabolism in liver, muscle, adipose tissue and gut. $\rightarrow$, normal metabolic pathway; $\rightarrow$, metabolic pathway increased as a result of increased lipolysis in adipose tissue; - , inhibition.

stored as triglyceride or oxidized to acetyl CoA. Acetyl $\mathrm{CoA}$ is converted into citric acid before its final oxidation to $\mathrm{CO}_{2}$ and water. Increased circulating fatty acids therefore lead to increased intramuscular fatty acyl CoA, acetyl CoA and citric acid. The accumulation of these three compounds has three important consequences which are respectively: inhibition of fatty acid synthesis, inhibition of pyruvate oxidation and inhibition of glycolysis. It is these three changes which are particularly characteristic of tissues from alloxan diabetic animals.

The effects of fatty acids on liver have been studied in much less detail but all the information available indicates that very similar consequences are to be expected. Recently it has been shown (Kruger, Carhart \& Austad, r964) that the perfusion of isolated liver by fatty acids leads to an increased output of glucose by this tissue. This result is completely in accord with the knowledge of the factors controlling glycolysis and gluconeogenesis in this tissue (Krebs, I964). It further reinforces the validity of the overall concept of the glucose-fatty acid cycle as a fundamental mechanism for the regulation of the oxidation of carbohydrate and fat.

If one accepts that any condition which leads to increased mobilization and oxidation of fatty acids will lead to a decrease in glucose utilization by muscle and increased gluconeogenesis (i.e. diabetes) then one is in a position to predict the diabetogenic effects of a number of nutritional and hormonal factors (Table $\mathrm{I}$ ). 
Table I. Conditions leading to decreased glucose utilization

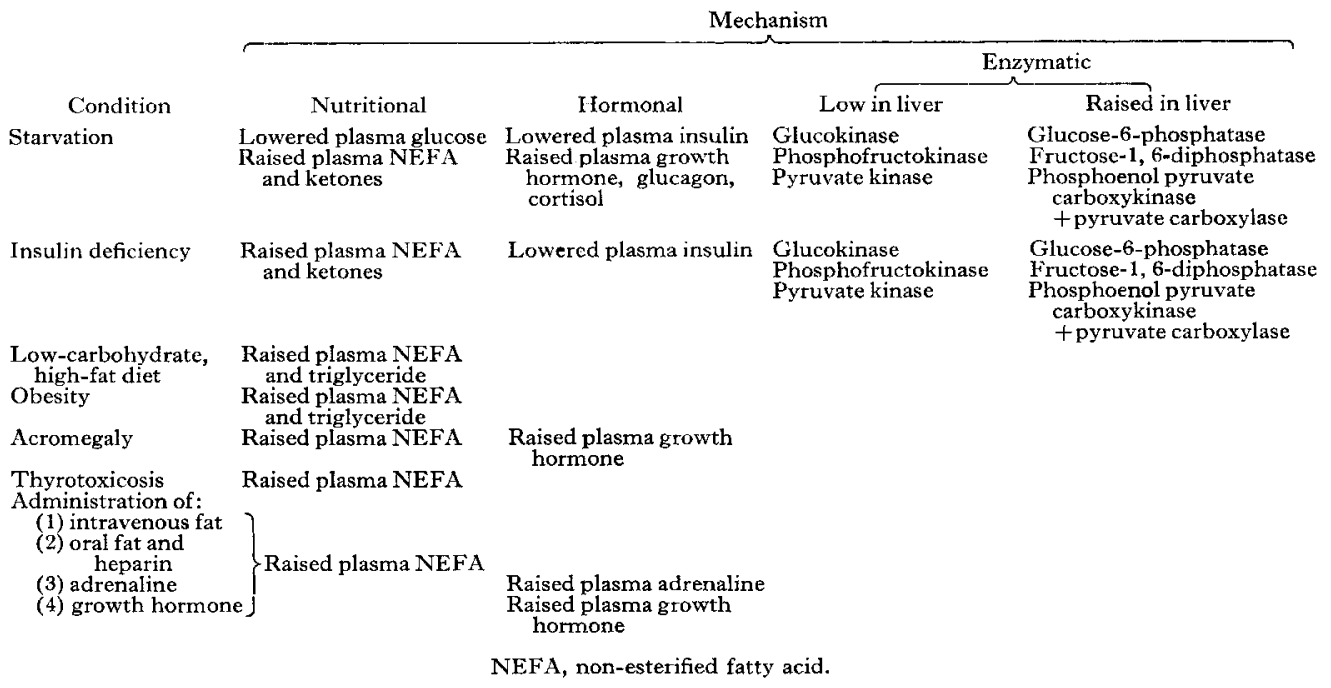

The corollary of this is that any substance which decreases fatty acid mobilization and oxidation will lead to increased glucose utilization by muscle and decreased gluconeogenesis (i.e. be anti-diabetic) (Table 2).

It is notable that there are relatively few factors known which are capable of reducing fatty acid release by adipose tissue.

The discovery that abnormalities of fatty acid metabolism may underlie the diabetogenic action of a large number of nutritional and hormonal factors prompted an investigation of fatty acid metabolism in diabetes mellitus. It has been shown that, during fasting, the concentrations of plasma non-esterified fatty acids are raised in diabetes mellitus (Bierman, Dole \& Roberts 1957). Plasma insulin concentrations were shown to be normal or raised in this condition (Yalow \& Berson, 1960). It therefore appeared important to establish whether patients with diabetes mellitus had elevated concentrations of plasma fatty acids in the presence of normal or raised plasma insulin and glucose concentrations (Hales \& Randle, r963; Hales, Walker, Garland \& Randle, i 965 ).

Individuals with the mildest reduction in carbohydrate tolerance had normal or supranormal concentrations of insulin but in spite of this the fasting fatty acid concentration was elevated and only fell to a normal post-glucose concentration $I \frac{1}{2}-2 \frac{1}{2} \mathrm{~h}$ after the intake of glucose. It is widely agreed that the fasting concentration of fatty acids is elevated in patients with diabetes mellitus. However it is sometimes said that the fatty acids fall normally after an intake of glucose or that the percentage fall is normal after glucose. As stated earlier, it is the absolute concentration of fatty acids which determines their rate of uptake by tissues. Therefore even if the plasma fatty acid concentration falls at a normal rate in diabetes (and usually it does not), starting at a higher level it is necessarily longer before the plasma fatty acid concentration of a diabetic falls to the same absolute concentration as that of a normal person after glucose administration. 
Table 2. Substances increasing glucose utilization

\begin{tabular}{|c|c|c|c|}
\hline & \multicolumn{3}{|c|}{ Mechanism } \\
\hline Substance & Nutritional & Hormonal & Enzymatic \\
\hline Glucose & $\begin{array}{l}\text { Raised plasma glucose } \\
\text { Lowered plasma NEFA } \\
\text { and tissue fatty acyl } \\
\text { CoA }\end{array}$ & $\begin{array}{l}\text { Raised plasma insulin } \\
\text { Lowered plasma growth } \\
\text { hormone }\end{array}$ & $\begin{array}{l}\text { Raised in liver: glucokinase, } \\
\text { phosphofructokinase, } \\
\text { pyruvate kinase }\end{array}$ \\
\hline Insulin & $\begin{array}{l}\text { Lowered plasma NEFA } \\
\text { and tissue fatty acyl } \\
\text { CoA }\end{array}$ & Raised plasma insulin & $\begin{array}{l}\text { Raised in liver: glucokinase, } \\
\text { phosphofructokinase, } \\
\text { pyruvate kinase }\end{array}$ \\
\hline Sulphonylureas & & Raised plasma insulin & \\
\hline Nicotinic acid & Lowered plasma NEFA & & \\
\hline Salicylate & Lowered plasma NEFA & & $\begin{array}{l}\text { Uncoupled oxidative } \\
\text { phosphorylation }\end{array}$ \\
\hline $\begin{array}{l}\text { 3,5-dimethyl- } \\
\text { isoxazole }\end{array}$ & $\begin{array}{l}\text { (?) lowered plasma } \\
\text { NEFA }\end{array}$ & & \\
\hline Hypoglycin & & & $\begin{array}{l}\text { Inhibition of fatty acid } \\
\text { oxidation }\end{array}$ \\
\hline
\end{tabular}

This point may be exemplified by considering the normal individual who whilst fasting is metabolizing mainly fatty acid. In order to change over to carbohydrate oxidation during feeding there is a rapid fall in the plasma fatty acid concentration from a value of $35^{\circ}-45^{\circ} \mu \mathrm{M}$ to the region of ${ }_{5} 5^{-}-200 \mu \mathrm{M}$. These values are of course approximate and take no account of intramuscular triglyceride breakdown as a source of fatty acid for oxidation. However, it is interesting that when the concentration of fatty acid necessary to reduce glucose uptake of the perfused rat heart was determined, it was found (Randle et al. I966) that concentrations of $200 \mu \mathrm{M}$ or less had little effect, but that an effect became manifest and maximal on going from the concentration of $200 \mu \mathrm{M}$ to $500 \mu \mathrm{M}$. This is just the range over which the normal plasma fatty acid fluctuates in going from the fed to the fasted state. It suggests that to enable the diabetic to utilize glucose at near-normal rates the plasma fatty acid concentration should be reduced to the region of $5_{50-200 \mu M}$. Here again it is not the rate at which the diabetic fatty acid concentration falls which is critical, but whether the absolute concentration falls to the normal concentration shortly after feeding.

The finding of a raised plasma fatty acid concentration in the presence of normal or supranormal plasma glucose and insulin concentrations has very important implications for the aetiology of diabetes mellitus. It signifies a loss of the normal insulin action on diabetic adipose tissue. Studies of the insulin-like activity of diabetic plasma on isolated rat adipose tissue have shown an elevated insulin-like activity (Steinke, Camerini, Marble \& Renold, 196r). This observation makes it unlikely that there is a circulating factor blocking glucose uptake or the action of 
insulin on glucose uptake by adipose tissue. Thus it would appear that there is an abnormality of diabetic adipose tissue such that it releases more fatty acid than normal. This could either be due to an increased breakdown of triglyceride or a decrease in the rate of esterification. The latter is dependent upon the rate of conversion of glucose into glycerol phosphate. Studies of isolated human diabetic adipose tissue (Carlson \& Ostman, I 963) have shown that the glucose consumption is greater than normal which makes it unlikely that the supply of glycerol phosphate is limited. Therefore there remains the possibility that enhanced breakdown of triglyceride is the primary abnormality leading to the abnormality of fatty acid metabolism seen in diabetes. Such an abnormality could arise from an intracellular defect or through the action of an external agent capable of stimulating triglyceride breakdown. A preliminary report describing the finding of increased activity in diabetic plasma of a factor stimulating triglyceride breakdown in rat adipose tissue has appeared (Recant, Alp, Koch \& Eggeman, I 963). This type of study is extremely difficult to control adequately and confirmation of this report would be valuable.

In conclusion it would appear that there is very strong evidence that the rate of oxidation of fatty acids is a factor of extreme importance in the physiological regulation of the rate of glucose utilization. The possibility exists that in diabetes mellitus there is a primary abnormality leading to increased availability of fatty acids for oxidation, that this is seen in the presence of normal or supranormal plasma insulin concentrations, and that it leads to impaired glucose utilization. This possibility could best be tested by means of a pharmacological agent which would unambiguously suppress fatty acid release and oxidation by a mechanism independent of insulin. Such a substance would almost certainly have the property of increasing insulin sensitivity. It would therefore be of use in the treatment of diabetes mellitus irrespective of the correctness of the above hypothesis.

I should like to thank Professor F. G. Young for his interest and encouragement.

\section{REFERENCES}

Ball, E. G. \& Jungas, R. L. (1964). Recent Prog. Horm. Res. 20, I83.

Bierman, E. L., Dole, V. P. \& Roberts, T. N. (I957). Diabetes, 6, 475.

Carlson, L. A., Boberg, J. \& Hogstedt, B. (1965). In Handbook of Physiology, Sect. 5. Adipose Tissue, p.625. [A. E. Renold and G. F. Cahill Jr., editors.] Washington, DC: American Physiological Society.

Carlson, L. A. \& Ostman, J. (1963). Acta med. scand. 174, 215.

Fain, J. N., Kovacev, V. P. \& Scow, R. O. (1965). F. biol. Chem. 240, 3522.

Hales, C. N. \& Randle, P. J. (1963). Lancet, i, 790 .

Hales, C. N., Walker, J. B., Garland, P. B. \& Randle, P. J. (1965). Lancet, i, 65.

Krebs, H. A. (1935). Biochem. F. 29, 1620.

Krebs, H. A. (1964). Proc. roy. Soc. B, 159, 545.

Kruger, F. A., Carhart, J. M. \& Austad, R. A. (1964) 7. Lab. clin. Med. 64, 876.

Munch, A. \& Koritz, S. B. (1962). Biochim. biophys. Acta, 57, 3 I 8

Randle, P. J., Garland, P. B., Hales, C. N.\& Newsholme, E. A. (I963). Lancet, i, 785.

Randle, P. J., Garland, P. B., Hales, C. N., Newsholme, E. A., Denton, R. M. \& Pogson, C. I. (Ig66). Recent Prog. Horm. Res, 22.

Recant, L., Alp, H., Koch, M. B. \& Eggeman, J. (1963). Lancet, ii, 614.

Steinke, J., Camerini, R., Marble, A. \& Renold, A. E. (1961). Metabolism, 1o, 707.

Yalow, R. S. \& Berson, S. A. (I960). F. clin. Invest. 39, 1157. 